\title{
Portable oxygen and exercise tolerance in patients with chronic hypoxic cor pulmonale
}

\author{
R J E LEGGETT, D C FLENLEY
}

British Medical fournal, 1977, 2, 84-86

\section{Summary}

Breathing $30 \%$ oxygen during exercise alleviated arterial hypoxaemia and reduced minute ventilation in patients with severe chronic bronchitis. A similar level of oxygen (2 or 4 litres of oxygen/minute) from nasal prongs also increased their exercise tolerance, as assessed by the distance that they could walk on the level in 12 minutes. Nevertheless, a single-blind controlled study showed that the effort of carrying their portable supply of liquid oxygen, in the Union Carbide Oxygen Walker, abolished this gain in exercise tolerance. The improvement in walking distance was restored when oxygen on exercise was provided by wheeling the oxygen walker on a lightweight shopping trolley.

\section{Introduction}

Breathlessness is the main symptom that limits exercise in patients with chronic hypoxic cor pulmonale. Although many factors, including the disordered mechanical properties of the lungs and thorax, ${ }^{12}$ contribute to this, we have found that even partial correction of the severe arterial hypoxaemia that these patients develop on exercise, by breathing $30^{\circ}{ }_{0}$ oxygen, can reduce their minute ventilation on exercise ${ }^{3}$ and may thereby improve their exercise tolerance. ${ }^{4}$ To assess this possibility, we measured ventilation, gas exchange, and arterial blood gas tensions in patients with chronic obstructive lung disease during bicycle and treadmill exercises when they breathed air and also $30^{\circ}{ }^{\circ}$ oxygen. We also measured the distance that they could walk within 12 minutes $^{j}$ when breathing air or oxygen provided through nasal prongs. We also performed a single-blind study of the effects of providing oxygen from a patient-carried supply of liquid oxygen (the Union Carbide Oxygen Walker).

\section{Patients and methods}

As part of the assessment for treatment with a long-term domiciliary oxygen supply, ${ }^{6}$ we studied 19 men and seven women who suffered from chronic hypoxic cor pulmonale with pulmonary hypertension as a result of their chronic obstructive lung disease. All were in a stable clinical state at the time of assessment, without peripheral oedema or chest infection, and had no progressive change in body weight, forced expiratory volume in 1 second $\left(\mathrm{FEV}_{1}\right)$, or arterial blood gas tensions $\left(\mathrm{PaO}_{2}, \mathrm{PaCO}_{2}\right.$ ) during the previous three weeks (table I). All performed either a treadmill or a progressive bicycle exercise when breathing air, and 15 patients also repeated the exercise when breathing $30 \%$ oxygen, the order of the air or oxygen studies being randomised. Minute ventilation $\left(\dot{\mathrm{V}}_{\mathrm{E}}\right)$, oxygen uptake $\left(\dot{\mathrm{V}}_{2}\right)$, carbon dioxide output $\left(\dot{\mathrm{V}}_{\mathrm{CO}}\right)$, $\mathrm{PaO}_{.,}, \mathrm{PaCO}_{2}$, and $\mathrm{pH}$ were measured as described previously."

In 16 patients we also measured the distance that they could walk on the level, at their own pace (including stops if so desired); within

Department of Medicine, Royal Infirmary, Edinburgh EH3 9YW

R J E LEGGETT, MB, MRCP, MRC research fellow

D C FLENLEY, PHD, FRCP, reader in medicine and honorary consultant physician
12 minutes. ${ }^{5}$ During this walk the patients received 2 or $4 \mathrm{l} / \mathrm{min}$ of a gas (either air or oxygen) through nasal prongs, but they did not know which gas they were receiving. Each patient walked twice when breathing each gas mixture, with a rest of at least 30 minutes between each walk and no more than four walks on the same day. The different gas mixtures were given in random order. Three subgroups were studied, some patients being common to each group: group 1 included eight patients who walked when breathing air or $2 \mathrm{l}$ of oxygen $/ \mathrm{min}$ with and without the oxygen walker. Group 2 comprised eight patients studied when breathing air or 41 of oxygen/min without carrying the walker, and also 2 or 41 of oxygen/min when carrying the oxygen, walker. Group 3 consisted of nine patients who underwent the same procedures as those in group 2 but they wheeled the oxygen walker on a modified shopping trolley. The significance of changes in the distance walked in 12 minutes was calculated by a paired $t$ test, each patient being compared with his own performance.

The oxygen walker, which weighs $4.5 \mathrm{~kg}$ when full of liquid oxygen and contains the equivalent of 1000 litres of gaseous oxygen, is designed to be carried over the shoulder. During the walks a gas (either air or oxygen at 2 or $41 / \mathrm{min}$ ) was provided to the nasal prongs from a covered cylinder which was wheeled behind the patient as he walked, so that he did not know what gas mixture he was receiving. In five patients arterial blood was sampled from an indwelling arterial cannula before and during the 12-minute walk.

\section{Results}

In patients performing both treadmill and bicycle exercises when

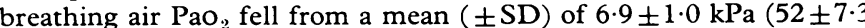
$\mathrm{mm} \mathrm{Hg})$ to $6.0 \pm 0.7 \mathrm{kPa}(45 \pm 5.3 \mathrm{~mm} \mathrm{Hg})$, but the $\mathrm{Paco}_{2}$ rose from a mean value of $6.9 \pm 1.6 \mathrm{kPa}(52.0 \pm 11.7 \mathrm{~mm} \mathrm{Hg})$ to only $7.5 \pm 1.0 \mathrm{kPa}$ $(56 \pm 7.5 \mathrm{~mm} \mathrm{Hg}) . \dot{\mathrm{V}}_{\mathrm{E}}$ was reduced during exercise in 12 out of 15

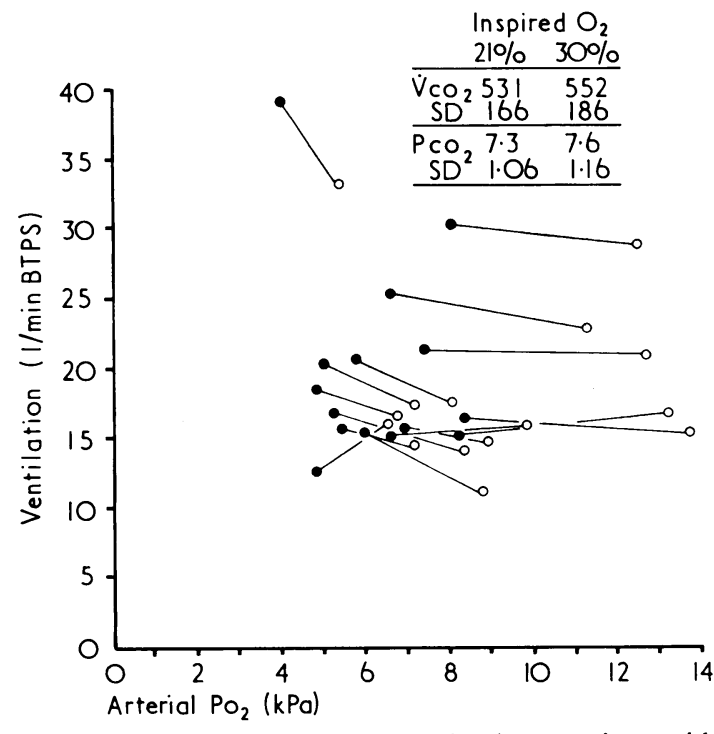

Ventilation and arterial oxygen tension in 15 patients with severe chronic bronchitis during exercise when breathing air $(O)$ and $30 \%$ oxygen $(O)$. Level of exercise was chosen so that metabolic cost, measured as $\mathrm{CO}_{2}$ output $\left(\mathrm{VCO}_{2} ; \mathrm{ml}\right.$ standard temperature and pressure $/ \mathrm{min}$ ), and arterial $\mathrm{PCO}_{2}$ $(\mathrm{kPa})$ were not significantly different when breathing air or $30 \%$ oxygen.

BTPS $=$ Body temperature and pressure, saturated.

Conversion: SI to traditional units- $\mathrm{PCO}_{2}: 1 \mathrm{kPa} \approx 7.5$ $\mathrm{mm} \mathrm{Hg}$. 
patients when they were breathing $30 \%$ oxygen compared with their values when they were breathing air at the same level of exercise, as assessed by the $\mathrm{CO}_{2}$ output $\left(\dot{\mathrm{VCO}}_{2}\right)$ (see figure). We expressed the metabolic cost of exercise in these patients by the $\dot{\mathrm{V}} \mathrm{CO}_{2}$ rather than the oxygen consumption $\left(\mathrm{V}_{2}\right)$ because of the changes in body stores of oxygen when the subjects are not breathing air.

The eight patients in group 1 walked on average 694 metres in 12 minutes when breathing air. Analysis of variance (table II) of all 64 measurements, including two replicate measurements on each patient with each of the four treatments (air alone; air while carrying the walker; 21 oxygen/min alone; and 21 oxygen $/ \mathrm{min}$ while carrying the walker), showed that the mean squares within and between replicates were similar, the variance between repeated walks being as great as that between patients. Therefore the pooled residual mean square was used to calculate the variance ratio. Breathing 21 oxygen $/ \mathrm{min}$ increased the average distance walked by $51.6 \mathrm{~m}$, but carrying the walker reduced it by $73.6 \mathrm{~m}$. As there was no significant interaction these effects were additive, so that carrying the walker reduced the distance walked by the same amount when breathing either air or oxygen. Thus carrying the walker when breathing oxygen did not increase the distance walked in 12 minutes over that when breathing air alone.

The eight patients in group 2 walked on average $711 \mathrm{~m}$ when breathing air alone (table III), with two replicate studies on each patient on each treatment (air alone; $4 \mathrm{l}$ oxygen/min alone; 21 oxygen/ min while carrying the walker; 41 oxygen $/ \mathrm{min}$ while carrying the walker). Analysis of variance (table IV) showed that the distance walked when the patients were breathing either 2 or 41 of oxygen $/ \mathrm{min}$ when carrying the walker was not significantly greater than when they were breathing air alone. The Studentised range test was used to assess the significance of these differences, as the differences between treatments were not independent.

Patients in group 3, all of whom increased their walking distance when breathing oxygen, wheeled the walker. Analysis of variance (table V) showed that here the within replicate variance should not be pooled with the error variance. Wheeling the walker when breathing 41 of oxygen/min significantly increased the average distance walked

TABLE 1-Clinical details of 26 patients with chronic bronchitis and emphysema

\begin{tabular}{|c|c|c|}
\hline Measurement & & Mean value $(t S D)$ \\
\hline 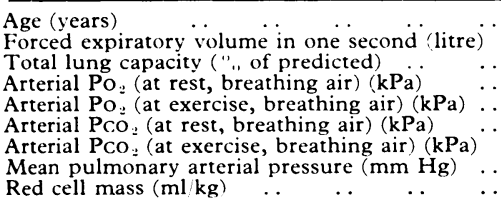 & $\begin{array}{l}\cdots \\
\cdots \\
\cdots \\
\cdots \\
\cdots \\
\cdots \\
\cdots\end{array}$ & $\begin{array}{l}59 \cdot 0: 1 \cdot 5 \\
0 \cdot 68: 0 \cdot 24 \\
103: 19 \\
6 \cdot 9=1 \cdot 0 \\
6 \cdot 0=0 \cdot 7 \\
6 \cdot 9=1 \cdot 6 \\
7 \cdot 4=1 \cdot 0 \\
34 \cdot 3=11 \cdot 7 \\
40 \cdot 2: 8 \cdot 3\end{array}$ \\
\hline
\end{tabular}

TABLE II-Analysis of variance of distance walked (in metres) in eight patients in group 1 when breathing air alone, air from the walker, 2 l oxygen min alone, and 2 l oxygen from the walker

\begin{tabular}{|c|c|c|c|c|}
\hline Source & DF & $\begin{array}{l}\text { Sum of } \\
\text { squares }\end{array}$ & $\begin{array}{r}\text { Mean } \\
\text { square }\end{array}$ & $\begin{array}{c}\text { Variance } \\
\text { ratio }\end{array}$ \\
\hline $\begin{array}{l}\text { Patients } \\
\text { Gas } \\
\text { Walker } \\
\text { Interaction: gas } \times \text { walker } \\
\text { Residual }\end{array}$ & $\begin{array}{r}7 \\
1 \\
1 \\
1 \\
53\end{array}$ & $\begin{array}{r}3141628 \\
42539 \\
86730 \\
\\
410 \\
146435\end{array}$ & $\begin{array}{r}448804 \\
42539 \\
86730 \\
410 \\
2763\end{array}$ & $\begin{array}{r}162 \cdot 4^{*} \\
15 \cdot 4^{*} \\
31 \cdot 4^{*} \\
0 \cdot 15\end{array}$ \\
\hline $\begin{array}{l}\text { Within replicates } \\
\text { Between replicates }\end{array}$ & $\begin{array}{l}32 \\
21\end{array}$ & $\begin{array}{l}86820 \\
59615\end{array}$ & $\begin{array}{l}2713 \\
2839\end{array}$ & \\
\hline Total & 63 & 3417743 & & \\
\hline
\end{tabular}

*Significant at 1 ". level.

Effect of 21 oxygen $/ \mathrm{min}=51.6 \mathrm{~m}$ increase $(\mathrm{SE}=13.1 \mathrm{~m})$.
Effect of carrying walker $=73.6 \mathrm{~m}$ decrease $(\mathrm{SE}=13 \cdot 1 \mathrm{~m})$.

TABLE III-Distance walked on different treatments in group 2

\begin{tabular}{l|c|c}
\hline & Metres & Mean change $(\lfloor$ SE) \\
\hline Air alone & 711 & \\
$41 \mathrm{O}_{2}$ min alone & 764 & $+53.12 \cdot 7 * *$ \\
$21 \mathrm{O}_{2}$ min from walker & 686 & $-25: 12 \cdot 7$ \\
$41 \mathrm{O}_{2}$ min from walker & 724 & $+13.12 \cdot 7$ \\
\hline
\end{tabular}

**Significant at $5 \%$, level on Studentised range test.
TABLE IV-Analysis of variance of distance walked (in metres) in eight patients in group 2 when breathing air alone, $4 \mathrm{l}$ oxygen'min alone, $2 \mathrm{l}$ oxygen/min from walker, and 4 l oxygen/min from walker

\begin{tabular}{|c|c|c|c|c|}
\hline Source & DF & $\begin{array}{l}\text { Sum of } \\
\text { squares }\end{array}$ & $\begin{array}{l}\text { Mean } \\
\text { square }\end{array}$ & $\begin{array}{c}\text { Variance } \\
\text { ratio }\end{array}$ \\
\hline $\begin{array}{l}\text { Patients } \\
\text { Treatments } \\
\text { Residual }\end{array}$ & $\begin{array}{r}7 \\
3 \\
53\end{array}$ & $\begin{array}{r}1261054 \\
51021 \\
68736\end{array}$ & $\begin{array}{r}180151 \\
17007 \\
12297\end{array}$ & $\begin{array}{l}138 \cdot 9^{*} \\
13 \cdot 1^{*}\end{array}$ \\
\hline $\begin{array}{l}\text { Within replicates } \\
\text { Between replicates }\end{array}$ & & $\begin{array}{l}24158 \\
44578\end{array}$ & $\begin{array}{ll}1 & 150 \\
1 & 393\end{array}$ & \\
\hline Total & & 138081 & & \\
\hline
\end{tabular}

*Significant at $1 "$ ". level.

TABLE V-Analysis of variance of distance walked (in metres) in nine patients in group 3 when breathing air alone, 4 l oxygen/min alone, 2 loxygen/min when wheeling walker, and 4 loxygen/min when wheeling walker

\begin{tabular}{|c|c|c|c|c|}
\hline Source & DF & $\begin{array}{l}\text { Sum of } \\
\text { squares }\end{array}$ & $\begin{array}{l}\text { Mean } \\
\text { square }\end{array}$ & $\begin{array}{c}\text { Variance } \\
\text { ratio }\end{array}$ \\
\hline $\begin{array}{l}\text { Patients } \\
\text { Treatments } \\
\text { Residual }\end{array}$ & $\begin{array}{r}8 \\
3 \\
60\end{array}$ & $\begin{array}{r}3000833 \\
60086 \\
48327\end{array}$ & $\begin{array}{rl}375 & 104 \\
20 & 029 \\
& 805.5\end{array}$ & $\begin{array}{l}227 \cdot 9 * \\
12 \cdot 2^{*}\end{array}$ \\
\hline $\begin{array}{l}\text { Within replicates } \\
\text { Between replicates }\end{array}$ & $\begin{array}{l}36 \\
24\end{array}$ & $\begin{array}{r}8832 \\
39495\end{array}$ & $\begin{array}{r}245 \cdot 3 \\
1645 \cdot 6\end{array}$ & \\
\hline Total & 71 & 3109246 & & \\
\hline
\end{tabular}

*Significant at 1 ". level.

TABLE VI-Distance walked on different treatments in group 3

\begin{tabular}{l|c|c}
\hline & Metres & Mean change $( \pm \mathrm{SE})$ \\
\hline Air alone & 696 & \\
$41 \mathrm{O}_{2}$ min alone & 771 & $+75 \pm 20 \cdot 3^{* *}$ \\
$21 \mathrm{O}_{2} /$ min wheeling walker & 730 & $+34 \pm 20 \cdot 3$ \\
$41 \mathrm{O}_{2}$ min wheeling walker & 755 & $+59 \pm 20 \cdot 3^{* *}$ \\
\hline
\end{tabular}

** Significant at 5 ", level on Studentised range test.

TABLE VII-Changes in arterial oxygen tensions $(\mathrm{kPa})$ during 12-minute walk in five patients

\begin{tabular}{|c|c|c|c|c|c|c|}
\hline \multirow{2}{*}{$\begin{array}{l}\text { Case } \\
\text { No }\end{array}$} & \multicolumn{2}{|c|}{ Air } & \multicolumn{2}{|c|}{$\begin{array}{c}21 \mathrm{O}_{2} / \mathrm{min} \\
\text { wheeling walker }\end{array}$} & \multicolumn{2}{|c|}{$\begin{array}{c}41 \mathrm{O}_{2} / \mathrm{min} \\
\text { wheeling walker }\end{array}$} \\
\hline & Rest & Exercise & Rest & Exercise & Rest & Exercise \\
\hline $\begin{array}{l}1 \\
2 \\
3 \\
4 \\
5\end{array}$ & $\begin{array}{l}8 \cdot 1 \\
6 \cdot 9 \\
8 \cdot 1 \\
6 \cdot 7 \\
7 \cdot 5\end{array}$ & $\begin{array}{l}6.4 \\
5 \cdot 5 \\
5 \cdot 9 \\
5 \cdot 7 \\
5.5\end{array}$ & $\begin{array}{r}12.4 \\
10.3 \\
8.9 \\
9 \cdot 3\end{array}$ & $\begin{array}{l}8 \cdot 4 \\
6 \cdot 4 \\
6 \cdot 8 \\
7 \cdot 6\end{array}$ & $\begin{array}{l}15 \cdot 0 \\
11 \cdot 3 \\
10 \cdot 3 \\
14 \cdot 1 \\
17 \cdot 2\end{array}$ & $\begin{array}{r}9 \cdot 5 \\
7 \cdot 2 \\
7 \cdot 6 \\
9 \cdot 2 \\
13 \cdot 1\end{array}$ \\
\hline Mean $\pm S D$ & $7.5+0.7$ & $5 \cdot 8: 0 \cdot 4$ & $10 \cdot 2 \pm 1 \cdot 6$ & $7 \cdot 3+0.9$ & $13 \cdot 6+2 \cdot 8$ & $9 \cdot 3 \div 2 \cdot 3$ \\
\hline $\begin{array}{l}\text { Mean fall in } \\
\text { PaO }^{\text {a }}\end{array}$ & \multicolumn{2}{|c|}{$1 \cdot 70.5$} & \multicolumn{2}{|c|}{$3 \cdot 1: 1 \cdot 0$} & \multicolumn{2}{|c|}{$4 \cdot 3 \pm 1 \cdot 1$} \\
\hline
\end{tabular}

by $59 \mathrm{~m}$ above that when breathing air alone (Studentised range test) (table VI). When wheeling the walker and breathing 21 of oxygen/min the increase of $34 \mathrm{~m}$ above that when breathing air alone was not significant.

Arterial $\mathrm{Po}_{2}$ fell in all the five patients in whom it was measured during the 12 -minute walk from $7.5 \pm 0.7 \mathrm{kPa}(56 \pm 5.3 \mathrm{~mm} \mathrm{Hg})$ to $5.8 \pm 0.4 \mathrm{kPa}(43.5 \pm 3.0 \mathrm{~mm} \mathrm{Hg})$ when breathing air, but provision of 21 of oxygen/min maintained $\mathrm{PaO}_{2}$ above the resting value when breathing air in two of the four patients. In one patient, however, even $4 \mathrm{l}$ of oxygen/min on walking failed to prevent his $\mathrm{PaO}_{2}$ falling to below the value which he enjoyed when at rest but breathing air (table VII).$$
\text { sl }
$$

\section{Discussion}

Aggravation of hypoxaemia by exercise is well recognised in patients with chronic obstructive lung disease ${ }^{389}$ and we have shown that severe hypoxaemia can occur during submaximal 
exercise during a 12-minute walk. The ventilatory response to hypoxia is potentiated during exercise in both normal subjects ${ }^{10}$ and most patients with severe chronic obstructive lung disease. ${ }^{3}$ Correction of this hypoxaemia during exercise might therefore be expected to reduce their minute volume at any given work load and thus render them less breathless. We have shown that this did occur in 12 of the 15 patients we have studied. In addition to this reduction in ventilatory drive during exercise, correction of hypoxaemia will also improve oxygen delivery to working muscles, so that the more hypoxic a patient becomes on exercise, the more adequate correction of the arterial hypoxaemia should improve exercise tolerance.

In this single-blind study we have shown that oxygen at 2 or $4 \mathrm{l} / \mathrm{min}$ administered through nasal prongs (corresponding to an inspired oxygen concentration of about $30^{\circ}{ }_{0}$ or $45^{\circ}$ o when at rest) will improve exercise tolerance in a selected group of patients with chronic hypoxic cor pulmonale. Nevertheless, in these patients, whose exercise tolerance is severely limited, even the small extra load of carrying the $4 \cdot 5-\mathrm{kg}$ oxygen walker is sufficient to completely offset the advantage obtained by breathing 2 or $4 \mathrm{l}$ of oxygen/min when walking. This disadvantage of the patient carrying his own oxygen supply can be overcome when he wheels the oxygen walker on a lightweight trolley. Although the increase in distance walked within the 12 minutes was small ( $59 \pm$ (SD) 42 metres), in the more severely disabled this may amount to $25^{\circ}$ o of the distance that they can walk in 12 minutes when breathing only air. When we considered only those patients whose 12-minute walking distance was less than 750 metres the mean increase in distance walked when breathing $4 \mathrm{l}$ of oxygen $/ \mathrm{min}$, but wheeling the oxygen walker, amounted to $87 \pm 25$ metres. It seems probable that if the oxygen flow rate from the nasal prongs were increased above $4 \mathrm{l} / \mathrm{min}$ there might be further improvement in the arterial $\mathrm{Po}_{2}$, for even at this level there was still significant hypoxaemia $\left(\mathrm{Po}_{2}\right.$ less than $8.0 \mathrm{kPa}(60 \mathrm{~mm} \mathrm{Hg})$ ) during exercise in two of our five patients. Nasal prongs, delivering oxygen to the anterior nares both in inspiration and expiration, are obviously a relatively inefficient means of supplying oxygen, but they have the outstanding advantage that they are well tolerated by patients, in contrast to a tight-fitting face mask, which although mechanically more efficient, cannot be tolerated by these patients for any length of time. ${ }^{11}$

Our studies suggest that oxygen during exercise can benefit severely hypoxic patients by allowing a small but statistically significant increase in the distance walked within 12 minutes. But we also found that provision of such oxygen from a patientcarried system, the Union Carbide Oxygen Walker, although convenient and practicable, does carry the disadvantage that the extra weight of the equipment hinders the patient's performance. We suggest that wheeling the oxygen walker on a simple, cheap, lightweight trolley will allow these breathless patients to derive benefit from oxygen during exercise, in addition to the undoubted benefit that they already obtain from having a portable supply of oxygen, which allows them to obtain oxygen therapy for at least 15 hours of the day, a period known to be necessary if objective benefit is to be obtained from long-term domiciliary oxygen therapy. ${ }^{612}$ Our results indicate that the challenge of providing this physiological benefit of oxygen on exercise from a patient-carried device remains a problem that the bioengineers have yet to solve.

We thank Mrs G M Raab, of the Medical Computing and Statistics Group, University of Edinburgh, for advice. RJEL was supported by the Medical Research Council.

Requests for reprints should be addressed to Dr D C Flenley.

\section{References}

1 Grimby, G, and Stiksa, J, Scandinavian Fournal of Clinical and Laboratory Investigation, 1970, 25, 303.

2 Potter, W A, Olafsson, S, and Hyatt, R E, fournal of Clinical Investigation 1971, 50, 910.

${ }^{3}$ King, A J, et al, Clinical Science, 1973, 44, 151.

4 Cotes, J E, Thorax, 1960, 15, 244.

${ }^{5}$ McGavin, C R, Gupta, S P, and McHardy, G J R, British Medical fournal, $1976,1,822$.

${ }^{6}$ Leggett, R J E, et al, Thorax, 1976, 31, 414.

${ }^{7}$ Hill, A V, Long, C N H, and Lupton, H, Proceedings of the Royal Society of London, 1924-5, series B, 97, 84.

${ }^{8}$ Cotes, J E, Piza, Z, and Thomas, A J, Clinical Science, 1963, 25, 305.

9 Jones, N L, Clinical Science, 1966, 31, 39.

10 Asmussen, E, and Nielsen, M, Acta Physiologica Scandinavica, 1958, 43, 365.

11 Green, J D, British Medical fournal, 1967, 3, 593.

12 Stark, R D, Finnegan, P, and Bishop, J M, British Medical fournal, 1973, 3, 467.

\section{Visual complications of mitral leaflet prolapse}

\section{A WILSON, P W N KEELING, A D MALCOLM, R W ROSS RUSSELL, M M WEBB-PEPLOE}

British Medical fournal, 1977, 2, 86-88

\section{Summary \\ Four young women and six older men with mitral leaflet prolapse presented with visual disturbances consistent with embolism in the ophthalmic or posterior cerebral circulation. Cardiac arrhythmias were common, but}

Middlesex Hospital Medical Schood, London WW1

L A WILSON, MB, MRACP, research fellow

St Thomas's Hospital, London SE1 1EH

$P$ W N KEELING, MRCP, medical registrar

A D MALCOLM, MSC, MRCP, locum senior medical registrar

$\mathrm{R}$ W ROSS RUSSELL, MD, FRCP, physician

M M WEBB-PEPLOE, MB, FRCP, cardiologist these are rarely associated with focal ischaemia. The evidence that mitral leaflet prolapse caused the embolism in these patients is suggestive but not conclusive. Further studies are needed. All patients with acute cerebral or ocular ischaemia should undergo thorough cardiovascular assessment, which should include routine echocardiography.

\section{Introduction}

The symptoms and physical signs associated with mitral leaflet prolapse have recently aroused much interest. ${ }^{12}$ Many patients with this condition have no symptoms, but some experience chest pain, palpitation, fatigue, or dyspnoea. Significant mitral regurgitation, infective endocarditis, serious arrhythmias, and, rarely, sudden death may occur. Malcolm et $a^{3}$ reviewed 85 patients with mitral leaflet prolapse, 11 of whom presented with 